\title{
The Economic Impact of Non-Melanoma Skin Cancer: A Review
}

\author{
Tejaswi Mudigonda; ${ }^{a}$ Daniel J. Pearce, MD; ${ }^{b}$ Brad A. Yentzer, MD;c Phillip Williford, MD; ${ }^{\mathrm{b}}$ and \\ Steven R. Feldman, MD, PhD; Notre Dame, Indiana, and Winston-Salem, North Carolina
}

\section{Key Words}

Non-melanoma skin cancer, treatments, care settings, Medicare,

costs, basal cell carcinoma, squamous cell carcinoma, BCC, SCC

\begin{abstract}
Non-melanoma skin cancer (NMSC) is the most common cancer in the United States. Cost of NMSC care primarily depends on 2 factors: care settings and treatment modalities. However, the cost efficacy of NMSC care has been insufficiently addressed in previous literature. Therefore, this article evaluates available research on the cost implications to compare the costs associated with treatment within different care settings and specialties involved, and to assess the costs of different treatment modalities with respect to procedure type, tumor size, and tumor location. This evaluation showed that physician-office settings provided the lowest cost per episode of care (\$492) and were the dominant setting for NMSC care; dermatologists managed most NMSC episodes and used a wider range of treatment options than other specialists. Regarding treatment modalities, Mohs micrographic surgery was shown to be similar in cost to traditional surgical excision with perma-
\end{abstract}

From the aCollege of Science, University of Notre Dame, Notre Dame, Indiana; and Departments of bermatologic Surgery, and 'Dermatology, Center for Dermatology Research, Wake Forest University School of Medicine, Winston-Salem, North Carolina. Submitted March 21, 2010; accepted for publication May 13, 2010. Tejaswi Mudigonda and Drs. Pearce and Yentzer have disclosed that they have no financial interests, arrangements, or affiliations with the manufacturers of any products discussed in the article or their competitors. Dr. Williford had disclosed that he is a consultant for or on the advisory board of Graceway Pharmaceuticals, LLC. Dr. Feldman has disclosed that he has financial relationships with Galderma; GlaxoSmithKline/Stiefel Laboratories Inc.; Astellas; Abbott Laboratories; Warner Chilcott; Centocor, Inc.; Amgen Inc.; Photomedex; Coria/Healthpoint/Valeant; Pharmaderm/Nycomed; Dermatology Foundation; American Society for Dermatologic Surgery; American Acne Rosacea Society; National Psoriasis Foundation; Ortho Pharmaceuticals; Aventis Pharmaceuticals; Roche Dermatology; 3M; Bristol-Myers Squibb Dermatology; Novartis Pharmaceuticals Corporation; Merck \& Co., Inc.; Xlibris Suncare Research; Peplin; Medscape; Kikaku; Caremark; Informa; and Medical Quality Enhancement Corporation.

Correspondence: Steven R. Feldman, MD, PhD, Department of Dermatology, Wake Forest University School of Medicine, Medical Center Boulevard, Winston-Salem, NC 27157-1071.

E-mail: sfeldman@wfubmc.edu nent sections and was less costly than excision with frozen sections. Electrodessication and curettage and imiquimod were also reported to be inexpensive treatments. Furthermore, a positive correlation was seen between cost and tumor size for any particular treatment modality. Given these comparisons, and the rising incidence of NMSC and potential legislative measures to regulate office-based procedures, it is important to preserve the low-cost management of this disease. (JNCCN 2010;8:888-896)

Non-melanoma skin cancers (NMSCs), characterized by malignant growth of the epithelial layer or external surface of the skin, are the most prevalent form of skin cancer in the United States. ${ }^{1}$ Since the 1960 s, the incidence of NMSC has increased $4 \%$ to $8 \%$ each year, with an estimated 1.4 million cases occurring in 2000 alone. ${ }^{1-6}$ NMSC is more common than lung, breast, prostate, and colon cancers combined. ${ }^{6,7}$ Basal cell carcinoma (BCC) and squamous cell carcinoma (SCC) constitute 75\% and $20 \%$ of all NMSCs, respectively. Although NMSC accounts for a low mortality, with approximately 2000 to 2500 deaths per year in the United States, it is associated with considerable patient morbidity. ${ }^{2,8-13}$

NMSC is generally a malignancy encountered in the elderly population, with Medicare the primary payer for most NMSC treatment. The estimated annual cost of NMSC care is $\$ 426$ million for the Medicare population and $\$ 650$ million for the entire United States population. ${ }^{14,15}$ NMSC Medicare costs, which are approximately 6 to 7 times greater than those for treating melanoma, rank fifth behind prostate, lung, colon, and breast carcinomas. ${ }^{16}$

The cost of NMSC care primarily depends on 2 factors: care settings and treatment modalities. NMSC treatment is provided in hospitals, ambulatory/outpatient surgical centers, and physician offices. NMSC 
is most commonly treated in the United States by dermatologists, although plastic surgeons, otolaryngologists, facial plastic surgeons, general surgeons, and family physicians also administer treatment. ${ }^{6,17,18}$ Treatment modalities for NMSC include excision and closure, electrodessication and curettage (EDC), cryosurgery, radiotherapy, topical treatment with imiquimod, and Mohs micrographic surgery (MMS).

A major goal of NMSC treatment is to remove the tumor while preserving maximal function and cosmesis. Cost is also an important consideration. The cost of NMSC treatment is affected by the size and location of the tumor. NMSC most commonly affects chronically sun-exposed sites, including the trunk and upper extremities, and particularly the head and neck. ${ }^{19}$ The 5-year recurrence rate for traditional surgical excision is $10.1 \%$ for primary BCC $^{20}$ and from $10.9 \%$ to $18.7 \%$ for SCC. ${ }^{21}$ The 5 -year cure rates of $99 \%$ reported for primary BCC and $95 \%$ to 97\% for SCC (lip) treated with MMS are unparalleled by any other modality. ${ }^{20,22}$

The substantial treatment costs have led to a reevaluation of how NMSC care should be delivered. The rise in NMSC incidence remains a personal burden to patients and a financial burden to the health care system.

This article summarizes the available research on the cost implications of NMSC, with a focus on comparing the costs of NMSC within different care settings and different physician groups involved, and evaluating results of recent studies comparing the cost of different treatment modalities with respect to procedure type, tumor size, and tumor location. Analysis and review of the current literature on costs for NMSC treatments and care settings will help direct policies and guidelines for the treatment of NMSC.

\section{Materials and Methods}

Using PubMed/MEDLINE, the authors conducted a systematic literature search for articles published between January 1990 and December 2009 containing information on the costs of NMSC. Potential studies were included if they provided an overview of the economic impacts of skin cancer while addressing NMSC as a subsection.

The authors reviewed 13 articles containing case reports and reviews describing the cost analyses and datasets associated with care settings, physician groups, and treatment modalities. To summarize the literature on the economics of NMSC management, the authors divided the analysis into 2 categories. The first category focuses on the broader issues of cost comparisons based on care settings and physician specialty, and the second analyzes NMSC treatment costs based on procedure type, lesion size, and lesion location.

\section{Data Sources Used for Acquiring Cost Information}

Literature data focusing on NMSC cost studies were obtained from the following surveys: the Medicare Current Beneficiary Survey (MCBS), National Ambulatory Medical Care Survey (NAMCS), National Hospital Discharge Survey (NHDS), and National Survey of Ambulatory Surgery (NSAS).

The Office of the Actuary, Center for Medicare \& Medicaid Services conduct the MCBS, a continuous and multipurpose survey of a nationally representative sample of Medicare population. The MCBS generates 2 forms of data: survey data (e.g., demographics, insurance coverage, medical conditions) and claims data that include Medicare Part A and Part B. Medicare claims data include all claims to Medicare for outpatient office visits and inpatient stays, including pathology and surgeons' fees. Data in the survey are included to determine sources of payment for all services used by Medicare beneficiaries, including copayments, deductibles, and noncovered services.

The NAMCS is conducted by the Division of Health Care Statistics of the National Center for Health Statistics (NCHS) to provide data on a representative sample of physician office visits in the United States. ${ }^{23}$ These data are weighted to produce national estimates that describe the use of ambulatory medical care services in the United States. The NHDS is a national probability survey providing information on inpatients discharged from nonfederal short-stay hospitals in the United States. ${ }^{24}$ Data are collected nationally from approximately 27,000 inpatient records from 500 hospitals. The NSAS is a representative survey performed from 1994 to 1996 that provides information about the use of ambulatory surgery services in the United States. ${ }^{25}$

\section{Cost Comparisons Based on Care Settings and Physician Specialty}

In the first study, data compiled from analysis of the 1992 to 1995 MCBS, 1992 to 1997 NHDS, 1996 NHDS, and 1994 to 1996 NSAS survey datasets were 
Mudigonda et al.

used to estimate Medicare expenditures and annual treatment costs in inpatient, ambulatory surgery, and physician office settings. ${ }^{26}$ In the second study, data compiled from 1998-1999 MCBS were analyzed to provide quantitative information on how frequently different specialists use different types of surgical options available for the treatment of NMSC. ${ }^{27}$ In the third study, data compiled from analysis of the 1999-2000 MCBS were used to determine Medicare payment per episode of NMSC care for different specialties involved. ${ }^{28}$

\section{Cost Comparisons of Treatments on the Basis of} Procedure Type, Tumor Location, and Tumor Size The authors then sought cost studies on NMSC treatments addressing differences in procedure type, tumor size, and tumor location. Of the 13 analyzed papers, 4 provide treatment cost evaluations with respect to procedure type, lesion size, and lesion location. The first 2 studies, using Current Procedural Terminology (CPT) codes, compared the cost effectiveness of MMS versus surgical excision. ${ }^{29,30}$

The third study compares costs for different treatment modalities for a BCC on the cheek and an SCC on the arm, using relative value units (RVUs) from the 2008 Resource-Based Relative Value Scale. ${ }^{31}$ RVUs, which determine insurance-based reimbursement for medical treatment, are assigned to the individual medical, surgical, or laboratory codes for procedures involved and any applicable facility charges. ${ }^{32}$ The fourth study analyzed data from the 1995 MCBS to determine the prevalence and treatment costs for NMSC treatment based on procedure type in Medicare patients older than 65 years. ${ }^{33}$

\section{Results}

\section{Cost Comparisons Based on Care Settings and Physician Specialty}

In the first study, Chen et al. ${ }^{26}$ estimated NMSC costs based on care settings (e.g., inpatient, ambulatory services, physician office), estimating the Medicare expenditures over a 4-year period (1992-1995 MCBS) and evaluating annual cost information for treatment procedures and episode of care (Table 1). Patients aged 65 years and older accounted for $65 \%$ of NMSC procedures identified in the NAMCS. ${ }^{26}$ Assuming that cost for each episode of NMSC treatment is similar in the Medicare and non-Medicare populations, the estimated cost for NMSC care for the entire United States population is $\$ 650$ million per year (\$426 million/0.65). ${ }^{26}$

Physician office settings provided the dominant setting for NMSC care, accounting for most of the total procedural costs $(76 \%)$ and the total procedures performed (91\%; Table 1). ${ }^{26}$ Physician office settings also offered the lowest cost per episode of care at $\$ 492 .^{26}$ The inpatient setting was the least frequent setting for NMSC care, accounting for the minority of the total procedural NMSC costs (9.6\%) and the total procedures performed (1.0\%). Inpatient settings provided the highest cost of episode per care at $\$ 5520 .{ }^{26}$

The next 2 studies by Manternach et al. ${ }^{27}$ and Chen et al. ${ }^{28}$ provide information regarding NMSC treatments based on specialty. The study by Chen et al. ${ }^{28}$ which assessed the cost of episodes of NMSC care according to specialty using MCBS data from 1999 to 2000, identified 497 episodes of NMSC care

Table 1 Estimated Medicare Expenditures and Procedures for Patients Aged 65 Years and Older

\begin{tabular}{|lllllll|} 
& $\begin{array}{l}\text { 1992-1995 } \\
\text { Total Medicare } \\
\text { Expenditures* }\end{array}$ & $\begin{array}{l}\text { Annual Number } \\
\text { of Skin Cancer } \\
\text { Treatment } \\
\text { Procedures }\end{array}$ & $\begin{array}{l}\text { Percentage } \\
\text { of Total } \\
\text { Procedures }\end{array}$ & $\begin{array}{l}\text { Estimated } \\
\text { Annual } \\
\text { Expenses }\end{array}$ & $\begin{array}{l}\text { Percentage } \\
\text { of Money } \\
\text { Spent Per } \\
\text { Year }\end{array}$ & $\begin{array}{l}\text { Cost Per } \\
\text { Episode } \\
\text { of Care }\end{array}$ \\
\hline Inpatient & $\$ 164,503,841$ & 7427 & $1.0 \%$ & $\$ 41,25,960$ & $9.6 \%$ & $\$ 5537$ \\
Ambulatory service & $\$ 243,197,087$ & 58,291 & $8.0 \%$ & $\$ 60,799,272$ & $14.3 \%$ & $\$ 1043$ \\
Physician office & $\$ 1,296,981,611$ & 658,472 & $91 \%$ & $\$ 324,245,403$ & $76.1 \%$ & $\$ 492$ \\
Total & $\$ 1,704,682,539$ & 724,190 & $100 \%$ & $\$ 426,170,635$ & $100 \%$ & $\$ 588$ \\
\hline
\end{tabular}

The number of skin cancer treatment procedures for ambulatory surgery and inpatient settings was obtained by identifying visits with an ICD-9 code of 173.x associated with an ICD-9 skin surgery code. For the physician's office setting, the number of identified procedures was divided by 2 with the assumption that $50 \%$ of total procedures obtained from the National Ambulatory Medical Care Survey were actual skin cancer procedures and the remaining $50 \%$ were biopsies.

*1992-1995 totals were obtained by summing the annual totals from the Medicare Current Beneficiary Survey. tObtained using 1992-1995 expenditures divided by 4. 


\begin{tabular}{|llll|}
\hline Table 2 & $\begin{array}{l}\text { Treatment Characteristics of Non- } \\
\text { Melanoma Skin Cancer Episodes in } \\
\text { 1999-2000 by Specialty }\end{array}$ & $\begin{array}{l}\text { Mean } \\
\text { Medicare } \\
\text { Payment }\end{array}$ \\
Specialty & Number & Percent & Paym \\
\hline $\begin{array}{l}\text { Dermatology } \\
\text { Surgery }\end{array}$ & 250 & 50.3 & $\$ 604$ \\
$\begin{array}{l}\text { Primary care } \\
\text { physician }\end{array}$ & 28 & 5.6 & $\$ 957$ \\
$\begin{array}{l}\text { Other physician } \\
\text { Multiple specialists }\end{array}$ & 129 & 6.6 & $\$ 296$ \\
\hline
\end{tabular}

from 372 patients based on their Medicare Part A and B claims. CPT codes were used to identify the itemized services. The Medicare allowable charged was applied to each itemized service to determine a value. ${ }^{28}$ The total cost of an episode of NMSC care was defined as the sum of all itemized allowable charges. The highest number of NMSC episodes $(50 \%)$ was encountered among dermatologists, with 250 of the 497 episodes studied (Table 2). ${ }^{28}$ The mean cost per episode for dermatologists was $\$ 604, \$ 957$ for surgeons, $\$ 877$ for multiple specialists, $\$ 296$ for primary care physicians, and $\$ 521$ for other physicians. ${ }^{28}$

To further illustrate treatment characteristics according to specialty, Manternach et al..$^{27}$ evaluated how frequently different specialists use various surgical options. A sample of the 1998 to 1999 Medi- care claims data showed 1,986,159 surgical NMSC episodes among Medicare beneficiaries. ${ }^{27}$ The physicians who performed the surgical interventions included dermatologists, plastic surgeons, general surgeons, and other specialties. ${ }^{27}$ Surgical procedures performed included biopsy, excision, destruction, and MMS. ${ }^{27}$ Dermatologists managed $82 \%$ of the NMSC episodes and used a wider range of treatment options than other specialists. ${ }^{27}$ Dermatologists performed $95 \%$ of the destructions, $90 \%$ of the biopsies, $56 \%$ of the excisions, and $100 \%$ of the MMS (Figure 1). ${ }^{27}$ Excision, destruction, and excision account for $88 \%$ of the procedures performed to treat NMSC, with dermatologists performing $82 \%$ of these common procedures. ${ }^{27}$

\section{Cost Comparisons of Treatments Based on Procedure Type, Tumor Location, and Tumor Size}

Four studies provide the most relevant comparisons for evaluating NMSC treatment costs. The first study by Cook and Zitelli ${ }^{29}$ evaluated treatment costs with respect to procedure type, comparing MMS with traditional methods of surgical excision (TSE). ${ }^{29}$ They reviewed 400 patients with NMSC undergoing treatment for primary tumors (337/400) and recurrent tumors (63/400). ${ }^{29}$ Costs of reimbursements for MMS were compared with those of the following TSE: 1 ) office excision with permanent sections, 2) office excision with frozen sections, and 3) ambulatory sur-

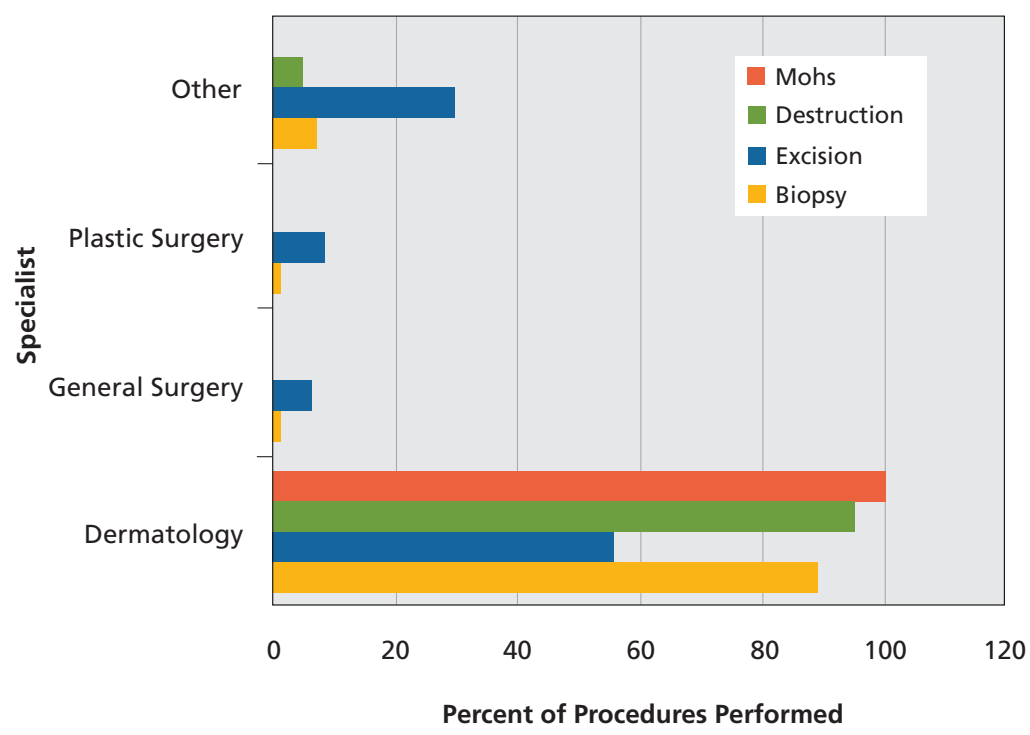

Figure 1. National estimates of surgical procedures for non-melanoma skin cancer according to specialty.

From Manternach T, Housman TS, Williford PM, et al. Surgical treatment of nonmelanoma skin cancer in the Medicare population. Dermatol Surg 2003;29:1167-1169, with permission. 
Mudigonda et al.

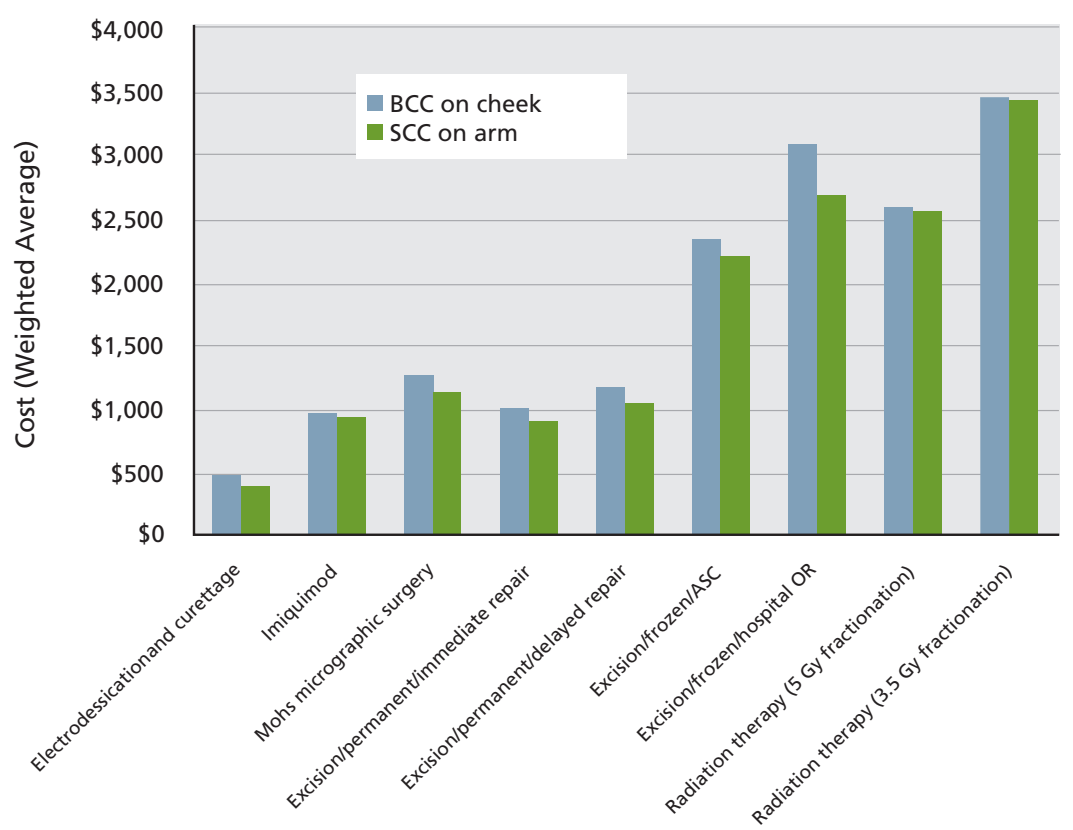

Figure 2. Cost comparison based on location of non-melanoma skin cancer treatment.

Bar graphs display weighted average costs of listed treatment modality for 4 tumor sizes: 0.6, 1.1, 2.1, and $3.1 \mathrm{~cm}$.

Abbreviations: ASC, ambulatory surgery center; OR, operating room.

Data from Rogers HW, Coldiron BM. A relative value unit-based cost comparison of treatment modalities for nonmelanoma skin cancer: effect of the loss of the Mohs multiple surgery reduction exemption. J Am Acad Dermatol 2009;61:96-103.

gery center excisions with frozen sections. ${ }^{29}$ Cook and Zitellii ${ }^{29}$ found that the cost for MMS (\$1243) was similar to that for excision with permanent sections (\$1167), ${ }^{29}$ but less than that for excision with frozen section margin control (\$1400 in an office setting, $\$ 1973$ in ambulatory surgery center). ${ }^{29}$

A successive study by Bialy et al..$^{30}$ also evaluated treatment costs with respect to procedure type, comparing the costs of MMS and TSE. ${ }^{30}$ MMS surgery was performed by a dermatologic surgeon and TSE by an otolaryngologist. ${ }^{30}$ Among 98 patients with NMSC of the face and ears, MMS was less costly (\$937) than TSE with either permanent (\$944$\$ 1029$ ) or frozen sections $(\$ 1399) .{ }^{30}$

A third study by Rogers and Coldiron ${ }^{31}$ used RVUs to provide a comprehensive estimation of costs of NMSC treatments based on location (BCC on cheek vs. SCC on forearm), tumor size $(0.6,1.1,2.1$, and $3.1 \mathrm{~cm}$ ), and procedure type (EDC, imiquimod immunotherapy, radiation therapy, MSS, TSE with permanent section margin evaluation in an office setting for both immediate and delayed repair, and surgical excision with frozen section for both ambulatory surgery center and hospital-based settings). ${ }^{31}$

Based on average treatment costs for each proce- dure type, $\mathrm{EDC}$ is the least expensive treatment modality for BCC on the cheek (\$471) and SCC on the arm (\$392; Figure 2). ${ }^{31}$ Imiquimod and office-based excision with permanent sections and immediate repair have approximately equal average costs of $\$ 959$ (BCC on cheek) and \$931 (SCC on arm) versus $\$ 1006$ (BCC on cheek) and \$907 (SCC on arm), respectively. ${ }^{31}$ The average costs of MMS, which were $\$ 1263$ (BCC on cheek) and \$1131 (SCC on arm), were more than double those of EDC and more expensive than those of imiquimod and TSE. ${ }^{31}$ More expensive treatments were excision with frozen section margin control in an ambulatory surgery center (BCC on cheek, \$2334; SCC on arm, \$2200) and in a hospital operating room (BCC on cheek, \$3085; SCC on arm, \$2680). ${ }^{31}$ The most expensive treatment was radiation therapy, with costs of $\$ 2591$ to $\$ 3460$ for BCC of the cheek and $\$ 2559$ to $\$ 3431$ for SCC of the arm. ${ }^{31}$

Regarding treatment costs based on tumor size, a positive correlation was seen between cost and tumor size for any particular treatment modality. For treatment costs based on tumor location, BCC of the cheek was more costly to treat than SCC of the arm for any given treatment modality (Figure 2). ${ }^{31}$ 
Economic Impact of Non-Melanoma Skin Cancer

Table 3 Assumptions of Studies Dealing With Economic Costs of NMSC Treatments

\begin{tabular}{|c|c|c|}
\hline Author & Objectives & Assumptions/Limitations of Cost Model \\
\hline Study & Purpose & Assumptions/Limitations \\
\hline Cook and Zitelli29 & $\begin{array}{l}\text { Cost comparison of } \\
\text { NMSC treatments based } \\
\text { on procedure type }\end{array}$ & $\begin{array}{l}\text { - All tumors would be excised with standard surgical margins; resultant } \\
\text { surgical defects would be reconstructed with simplest method possible } \\
\text { - Costs may vary according to surgeon expertise, laboratory setting, decisions } \\
\text { to repair or use second-intention healing, and tumor complexity }\end{array}$ \\
\hline Bialy et al. ${ }^{30}$ & $\begin{array}{l}\text { Cost comparison of } \\
\text { NMSC treatments based } \\
\text { on procedure type }\end{array}$ & $\begin{array}{l}\text { - Surgery setting and type of margin analysis for surgical excision (frozen or } \\
\text { permanent) were chosen by individual physicians } \\
\text { - All deep margins were clear with traditional surgical excision, which if } \\
\text { not true would lead to greater costs because further procedures and } \\
\text { complicated repairs would be necessary } \\
\text { - Reconstructive approach used was similar to that for initial tumor } \\
\text { - The study's MMS surgeon, who was aware that costs were primary outcome, } \\
\text { may have been predisposed toward second-intention healing }\end{array}$ \\
\hline $\begin{array}{l}\text { Rogers and } \\
\text { Coldiron }^{31}\end{array}$ & $\begin{array}{l}\text { Thorough cost analysis } \\
\text { to assess NMSC } \\
\text { treatment costs based } \\
\text { on procedure type, } \\
\text { tumor size, and } 2 \text { most } \\
\text { commonly diagnosed } \\
\text { NMSC locations }\end{array}$ & $\begin{array}{l}\text { - Assumptions regarding recurrence rates and positive margins were used } \\
\text { - For MMS, it was assumed that } 24 \% \text { of the cases were cleared with one MMS } \\
\text { stage, and } 76 \% \text { required additional stage for margin clearance } \\
\text { - For traditional surgical excision with permanent section margins, it was } \\
\text { assumed skin cancers were excised with 4-mm margins for BCC and 6-mm for } \\
\text { SCC }\end{array}$ \\
\hline Joseph et al..$^{33}$ & $\begin{array}{l}\text { Cost comparison based } \\
\text { on procedure type on a } \\
\text { per-person and annual } \\
\text { basis }\end{array}$ & $\begin{array}{l}\text { - NMSC costs are more accurately evaluated using CPT codes of Medicare } \\
\text { claims data } \\
\text { - Analysis of available data was limited in its ability to answer questions about } \\
\text { number of treatments required for each tumor } \\
\text { - Total number of NMSC lesions that each individual patient had was difficult } \\
\text { to calculate }\end{array}$ \\
\hline
\end{tabular}

Abbreviations: BCC, basal cell carcinoma; CPT, current procedural terminology; MMS, Mohs micrographic surgery; NMSC, nonmelanoma skin cancer; SCC, squamous cell carcinoma.

The fourth study by Joseph et al..$^{33}$ analyzes cost comparisons among the most common treatment modalities. The procedures included the following: 1) destruction, malignant, 2) excision, malignant, 3) MMS, and 4) radiation therapy..$^{33}$ The total costs for all NMSC treatments were approximately $\$ 285$ million. ${ }^{33}$ Surgical excision of tumors accounted for most of the annual costs, at $\$ 97.2$ million, and had a 35\% frequency. ${ }^{33}$ The total cost per patient treated was the highest for radiation therapy, at $\$ 1303$, whereas the least expensive charge per patient was for destruction of tumors, at $\$ 221 .{ }^{33}$ Overall, each study offers unique advantages in terms of cost efficacy but is limited by assumptions made within its cost model (Table 3).

\section{Discussion}

NMSCs account for more than 50\% of all cancers, and therefore management and treatment are considerable. Nevertheless, annual data show that costs of NMSC treatment account for less than 1\% of the $\$ 107$ billion spent annually on cancer care in the United States. ${ }^{6}$ The magnitude of total NMSC costs is currently low because the disease is managed effectively and efficiently. However, analyzing cost-effective care is difficult for at least 2 major reasons: 1) significant variability exists in the delivery of NMSC care in the United States, which affects cost efficiency, and 2) every cost study is completely dependent on the limitations and assumptions made in the model. Therefore, no universally accepted model exists for cost analysis of NMSC treatment. In the face of burgeoning health care reform, critical analysis of the cost of NMSC treatment is particularly timely.

Chen et $\mathrm{al}^{28}$ assessed the cost of episodes of NMSC care according to specialty using MCBS data from 1999 to 2000. The mean Medicare payment is less costly for dermatologists than other surgeons, at $\$ 604$ and $\$ 957$, respectively, with the lower costs 
Mudigonda et al.

likely because of dermatology practice being based in the outpatient setting (as opposed to surgical center or hospital)..$^{28}$ In addition, a disparity in surgical management of malignant and premalignant skin conditions exists between dermatologists and other specialties. ${ }^{18}$ Dermatologists, who make most of the annual NMSC diagnoses, have a wider surgical armamentarium and use these procedures more frequently than other specialties. ${ }^{27}$ Given these results, greater interdisciplinary training may have significant advantages in helping physicians in one specialty learn how specialists in other areas manage the disease.

With regard to care settings, the physician office offered the predominant and least costly ( $\$ 492$ per episode) setting for surgical management of NMSC compared with ambulatory/outpatient surgical centers and inpatient settings. ${ }^{26}$ Furthermore, physician offices provide nearly $91 \%$ of annual procedures and represent $76.1 \%$ of the money spent per year on NMSC treatment procedures. ${ }^{26}$

Recently, different state medical boards, legislatures, and medical associations have considered establishing laws to regulate office-based surgery. ${ }^{34}$ One study comparing treatment in ambulatory surgery centers with surgery performed in office settings in Florida cautioned against the latter based on the finding of a 10 -fold increased risk of adverse events and deaths. ${ }^{35}$ However, in a follow-up study, Venkat et al. ${ }^{36}$ critiques this conclusion of increased mortality risk, citing that a major limitation was the lack of uniform collection of the number of cases performed, reporting that death rates are very low $(<1$ per 100,000 procedures) in both physician's offices and ambulatory care centers. ${ }^{36}$ Because of the limited risk and low cost per episode of care in the office setting relative to inpatient and ambulatory surgery centers, office-based settings can provide the optimal setting for NMSC management.

At the core of NMSC management is the issue of cost differences in procedure type. Critical review of several studies is essential to guide health care policy and reimbursement decisions made by both Medicare and private insurers. The first 2 studies by Cook and Zitelli ${ }^{29}$ and Bialy et al. ${ }^{30}$ are useful because they provide a cost comparison of NMSC treatments based on procedure type. Both studies support MSS as cost-effective compared with traditional surgical excision for treating certain tumors.

Cook and Zitelli ${ }^{29}$ found that MMS (\$1243) was similar in cost to excision with permanent sections (\$1167). However, excision with frozen section margin control was more costly ( $\$ 1400$ in an office setting, $\$ 1973$ in ambulatory surgical centers) than MMS (\$1243). ${ }^{29}$ Consistent with this study, Bialy et al. ${ }^{30}$ found that MMS (\$937) was less costly than traditional surgical excision with either permanent (\$944-\$1029) or frozen sections (\$1399). Importantly, Cook and Zitelli ${ }^{29}$ discovered that subsequent reconstruction of tumors initially treated with MMS was often less complicated or less extensive than for tumors not treated with MMS. Economically, the higher cure rates of MMS reduce the overall 5-year cost of treating NMSC, because only $1 \%$ of cases require re-treatment compared with approximately $10 \%$ of cases treated with routine surgical excision. ${ }^{20}$

Although MMS is associated with consistently lower rates of recurrence, it has been found to be more time-consuming, resulting in higher total operative costs than surgical excision in the treatment of recurrent facial BCC. ${ }^{37}$ Other authors have found that the cost of a Mohs' procedure increases with an increasing number of stages. ${ }^{38}$ However, for BCC tumors eradicated in one stage and with strict indication criteria (e.g., indistinct tumor borders, aggressive histopathologic subtype, large tumors), MMS was less expensive than managing a recurrence treated too late. ${ }^{39}$ For patients with NMSC tumors with high risk of recurrence, it seems more cost-effective to undergo $1 \mathrm{MMS}$ surgery than 2 or more excisions, including other indirect costs. Nevertheless, future studies should continue to determine the significance of costs associated with MMS and surgical excision for treating recurrent carcinomas.

In a cost analysis comparing different treatment modalities, including MMS and TSE, Rogers and Coldiron $^{31}$ found that EDC and imiquimod were least expensive for treating both BCC on the cheek and SCC on the arm. ${ }^{31}$ Furthermore, these results reaffirmed those in the study by Chen et al. ${ }^{26}$ that inpatient/ambulatory surgery center-based excisions are substantially more expensive than office-based procedures and treatments. ${ }^{31}$ However, although EDC and imiquimod may seem to be the preferred treatments for these reasons, several limitations exist. Both treatment modalities have significant recurrence rates and both are not appropriate for all NMSC. ${ }^{40}$ One difficulty in conducting an economic analysis of skin cancer treatment is including patient 
Economic Impact of Non-Melanoma Skin Cancer

satisfaction or cosmesis in the numbers of interest. EDC, in particular, has been associated with inferior cosmetic outcomes compared with excision procedures, although no indirect cost has been assigned. ${ }^{41}$

In the final study, Joseph et al. ${ }^{33}$ showed that destruction of tumors seems to be the least costly method and is used for nearly one third of treatments. More expensive and complex treatments, such as MMS, excision, and radiation therapy, are reserved for more complex, high-risk, and recurrent tumors. ${ }^{33}$ This study had several limitations, including the fact that data analysis was limited in its ability to answer questions about number of treatments per tumor, and that calculating the total number of NMSC lesions may have been difficult. ${ }^{33}$ Although the costs per patient for MMS (\$899) are perceived to be higher than for other treatments, except radiation therapy, the procedure has considerable advantages: ${ }^{33}$ it is associated with low recurrence rates and requires no second excision for initially positive margins, resulting in fewer patient visits. ${ }^{33} \mathrm{~A}$ responsible provider considers all of these factors, whether consciously or not, when recommending treatment.

Physicians today must be scrupulous stewards of the health care dollar. In the case of NMSC, this translates to appropriate personnel treating a given tumor in the safest possible setting using the most cost-effective treatment. Although no one approach is rational for all tumors, efficacy of the procedure and site of the tumor may dictate future recurrence rates and more significant cosmetic concerns or morbidities, which should factor into complex medical decision making. In the end, treatment of a given cancer is highly individual and best not decided based on algorithms and cost models. However, based on these case studies, it is important to acknowledge that office-based procedures, such as EDC, TSE, and MMS, are the most cost-effective options and very safe. ${ }^{42}$ Future changes in reimbursement schemes will have effects on access and delivery of care that may be far reaching and difficult to predict.

\section{References}

1. Miller DL, Weinstock MA. Nonmelanoma skin cancer in the United States: incidence. J Am Acad Dermatol 1994;30:774-778.

2. Strom SS. Epidemiology of basal and squamous cell carcinoma of the skin. In: Miller MJ, Weber RS, Goepfert H, eds. Basal and Squamous Cell Skin Cancers of the Head and Neck. Baltimore: Williams \& Wilkins; 1996:1-7.
3. Skidmore RA Jr, Flowers FP. Nonmelanoma skin cancer. Med Clin North Am 1998;82:1309-1323.

4. Green A. Changing patterns in incidence of non-melanoma skin cancer. Epithelial Cell Biol 1992;1:47-51.

5. Glass AG, Hoover RN. The emerging epidemic of melanoma and squamous cell skin cancer. JAMA 1989;262:2097-2100.

6. American Cancer Society. Cancer Facts \& Figures 2000. Available at: http://www.cancer.org. Accessed August 3, 2010.

7. Freedberg KA, Geller AC, Miller DR, et al. Screening for malignant melanoma: a cost-effectiveness analysis. J Am Acad Dermatol 1999;41:738-745.

8. Gloster HM Jr, Brodland DG. The epidemiology of skin cancer. Dermatol Surg 1996;22:217-226.

9. National Cancer Institute. Surveillance Epidemiology and End Results. Cancer Cancer Statistics Review 1999. Available at: seer. cancer.gov. Accessed August 3, 2010.

10. Boring CC, Squires TS, Tong T, Montgomery S. Cancer statistics, 1994. CA Cancer J Clin 1994;44:7-26.

11. Weinstock MA. Epidemiologic investigation of nonmelanoma skin cancer mortality: the Rhode Island Follow-Back Study. J Invest Dermatol 1994;102:6S-9S.

12. Weinstock MA, Bogaars HA, Ashley M, et al. Nonmelanoma skin cancer mortality. A population-based study. Arch Dermatol 1991;127:1194-1197.

13. Weinstock MA. Nonmelanoma skin cancer mortality in the United States, 1969 through 1988. Arch Dermatol 1993;129:1286-1290.

14. Chen JG, Fleischer AB Jr, Smith ED, et al. Cost of non-melanoma skin cancer treatment in the United States. Dermatol Surg 2001;27:1035-1038.

15. Fleischer AB Jr, Feldman SR, Barlow JO, et al. The specialty of the treating physician affects the likelihood of tumor-free resection margins for basal cell carcinoma: results from a multi-institutional retrospective study. J Am Acad Dermatol 2001;44:224-230.

16. Housman TS, Feldman SR, Williford PM, et al. Skin cancer is among the most costly of all cancers to treat for the Medicare population. J Am Acad Dermatol 2003;48:425-429.

17. Fleischer AB Jr, Feldman SR, White RE, et al. Procedures for skin diseases performed by physicians in 1993 and 1994: analysis of data from the National Ambulatory Medical Care Survey. J Am Acad Dermatol 1997;37:719-724.

18. Smith ES, Feldman SR, Fleischer AB Jr, et al. Characteristics of office-based visits for skin cancer. Dermatologists have more experience than other physicians in managing malignant and premalignant skin conditions. Dermatol Surg 1998;24:981-985.

19. Roenigk RK, Ratz JL, Bailin PL, Wheeland RG. Trends in the presentation and treatment of basal cell carcinomas. J Dermatol Surg Oncol 1986;12:860-865.

20. Rowe DE, Carroll RJ, Day CL Jr. Long-term recurrence rates in previously untreated (primary) basal cell carcinoma: implications for patient follow-up. J Dermatol Surg Oncol 1989;15:315-328.

21. Rowe DE, Carroll RJ, Day CL Jr. Prognostic factors for local recurrence, metastasis, and survival rates in squamous cell carcinoma of the skin, ear, and lip. Implications for treatment modality selection. J Am Acad Dermatol 1992;26:976-990.

22. Kibarian MA, Hruza GJ. Nonmelanoma skin cancer. Risks, treatment options, and tips on prevention. Postgrad Med 1995;98:39-48.

23. Centers for Disease Control and Prevention. National Center for Health Statistics. National Ambulatory Medical Care Survey 1996. Public use data tape. Available at: ftp://ftp.cdc.gov/pub/ 
Mudigonda et al.

Health_Statistics/NCHS/Datasets/NAMCS/. Accessed August 10, 2010.

24. Centers for Disease Control and Prevention. National Center for Health Statistics. National Hospital Discharge Survey. Available at: http://cdc.gov/nchs/nhds.htm. Accessed August 10, 2010.

25. Centers for Disease Control and Prevention. National Center for Health Statistics. National Survey of Ambulatory Surgery. 2010 Available at: http://www.cdc.gov/nchs/nsas.htm. Accessed August 10, 2010.

26. Chen JG, Fleischer AB Jr, Smith ED, et al. Cost of nonmelanoma skin cancer treatment in the United States. Dermatol Surg 2001;27:1035-1038.

27. Manternach T, Housman TS, Williford PM, et al. Surgical treatment of nonmelanoma skin cancer in the Medicare population. Dermatol Surg 2003;29:1167-1169.

28. John CG, Yelverton CB, Polisetty SS, et al. Treatment patterns and cost of nonmelanoma skin cancer management. Dermatol Surg 2006;32:1266-1271.

29. Cook J, Zitelli JA. Mohs micrographic surgery: a cost analysis. J Am Acad Dermatol 1998;39:698-703.

30. Bialy TL, Whalen J, Veledar E, et al. Mohs micrographic surgery vs traditional surgical excision: a cost comparison analysis. Arch Dermatol 2004;140:736-742.

31. Rogers HW, Coldiron BM. A relative value unit-based cost comparison of treatment modalities for nonmelanoma skin cancer: effect of the loss of the Mohs multiple surgery reduction exemption. J Am Acad Dermatol 2009;61:96-103.

32. Wasserman Y. Physicians' Fee Reference 2008. Wasserman Medical Publishers: 2008.

33. Joseph AK, Mark TL, Mueller C. The period prevalence and costs of treating nonmelanoma skin cancers in patients over 65 years of age covered by medicare. Dermatol Surg 2001;27:955-959.
34. $\mathrm{AAD}$ and $\mathrm{ASDS}$ mobilize to address state-based regulation of office-based dermatologic surgery. Dermatology World 1999;9:8-9.

35. Vila H Jr, Soto R, Cantor AB, Mackey D. Comparative outcomes analysis of procedures performed in physician offices and ambulatory surgery centers. Arch Surg 2003;138:991-995.

36. Venkat AP, Coldiron B, Balkrishnan R, et al. Lower adverse event and mortality rates in physician offices compared with ambulatory surgery centers: a reappraisal of Florida adverse event data. Dermatol Surg 2004;30:1444-1451.

37. Smeets NW, Krekels GA, Ostertag JU, et al. Surgical excision vs Mohs' micrographic surgery for basal-cell carcinoma of the face: randomised controlled trial. Lancet 2004;364:1766-1772.

38. Welch ML, Anderson LL, Grabski WJ. Evaluation and management of nonmelanoma skin cancer. The military perspective. Dermatol Clin 1999;17:19-28.

39. Smeets NW, Kuijpers DI, Nelemans P, et al. Mohs' micrographic surgery for treatment of basal cell carcinoma of the face-results of a retrospective study and review of the literature. Br J Dermatol 2004;151:141-147.

40. Rodriguez-Vigil T, Vazquez-Lopez F, Perez-Oliva N. Recurrence rates of primary basal cell carcinoma in facial risk areas treated with curettage and electrodesiccation. J Am Acad Dermatol 2007;56:91-95.

41. Kuijpers DI, Thissen MR, Berretty PJ, et al. Surgical excision versus curettage plus cryosurgery in the treatment of basal cell carcinoma. Dermatol Surg 2007;33:579-587.

42. Coldiron BM, Healy C, Bene NI. Office surgery incidents: what seven years of Florida data show us. Dermatol Surg 2008;34:285291. 